В.г. АКИМКИН, чл.-корр. РАМН, д. м.н., профессор

ФБУН «НИИ дезинфектологии Роспотребнадзора», Москва

Первый МГМУ им. И. М. Сеченова

ФБУН «Центральный НИИ эпидемиологии» Роспотребнадзора, Москва

\title{
СОВРЕМЕННЫЕ АСПЕКТЫ ЭПИДЕМИОЛОГИИ \\ И ПРОФИЛАКТИКИ НОЗОКОМИАЛЬНОГО САЛЬМОНЕЛЛЕЗА
}

\section{Внутрибольничные инфекции являются острой проблемой современного здравоохранения в связи с высоким уровнем заболеваемости и летальности, а также значительным социально-экономическим ущербом, причиняемым ими. Среди многообразия их нозоформ значимая роль принадлежит сальмонеллезной инфекции [1-3, 5, 9-12].}

Ключевые слова: әпидемиология, внутрибольничные инфекции, сальмонеллез, бактериофаг

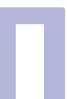

ервые публикации, касающиеся описания вспышек нозокомиального сальмонеллеза, относятся к 19501960-м гг. Все они характеризовали очаги инфекции, возникавшие в детских стационарах, когда в эпидемический процесс вовлекались главным образом дети в возрасте до 1 года и новорожденные. Но особую актуальность проблема нозокомиального сальмонеллеза приобрела в 1970-е гг,, когда на долю внутрибольничных вспышек, этиологически обусловленных главным образом S. typhimurium, приходилось от 25 до 40\% общей заболеваемости населения сальмонеллезами [3, 6, 7, 14].

Однако в 1990-е гг. отмечены существенные изменения в структуре пациентов лечебно-профилактических учрежде-

\section{В настоящее время сальмонеллез все чаще} стал поражать взрослых пациентов, удельный вес которых в последние годы в общей структуре регистрируемых случаев дoxodum $\partial 0$ 60-70\%

ний (ЛПУ), страдающих данной внутрибольничной инфекцией (ВБИ). Рассматриваемый ранее как нозокомиальная инфекция, присущая для детей раннего возраста, в настоящее время сальмонеллез все чаще стал поражать взрослых пациентов, удельный вес которых в последние годы в общей структуре регистрируемых случаев доходит до 60-70\%. Сальмонеллез, протекая на фоне серьезной соматической патологии, характеризуется тяжелым течением и значительной летальностью таких пациентов [1-6, 11, 12].

Указанная ситуация не является исключительной для России. Аналогичные данные в последние годы сообщают в публикациях исследователи из Франции, США, Италии, Испании, Китая, Великобритании, Латвии, Израиля и других стран [15-18]. С учетом современных тенденций изучение клинико-эпидемиологических особенностей этой инфекции и разработка комплекса мероприятий по ее профилактике в стационарах для взрослых являются важной научно-практической задачей.

Рассмотрение современных клинико-эпидемиологических особенностей данной инфекции наиболее оптимально, если использовать модель хронической эпидемии нозокомиального сальмонеллеза со значительным количеством заболевших, имевшей место в одном из крупных многопрофильных стационаров для взрослых.

Возбудитель инфекции - крайне важная составляющая часть эпидемического процесса. Характеризуя сальмонеллез как ВБИ, необходимо отметить важную особенность, имеющую, по мнению большинства исследователей, едва ли не решающее значение, а именно биологические свойства возбудителей. Это связано с тем, что практически все описанные внутрибольничные вспышки сальмонеллезов (за исключением пищевых) вызывают возбудители, отличающиеся одним общим свойством - множественной устойчивостью к химиотерапевтическим препаратам, и в первую очередь к антибиотикам $[1-3,14]$. Следует подчеркнуть, что в подавляющем большинстве случаев (более 80\%) возбудителем нозокомиального сальмонеллеза как в России, так и за рубежом является S. typhimurium. Это обусловлено особыми биологическими свойствами данного серовара, который приобрел в последние десятилетия выраженные черты «госпитального штамма».

Комплексное изучение более 2500 культур S. typhimurium, изолированных от больных и из внешней среды при обследовании крупного очага нозокомиального сальмонеллеза, позволило выявить сходство морфологических, серологических, биохимических и молекулярно-генетических свойств подавляющего числа выделенных госпитальных штаммов возбудителя (97-98\%), наличие целого ряда факторов вирулентности - антилизоцимной активности, адгезивности, инвазивности, впервые установленного свойства - IgAпротеазной активности (1998), а также выраженную устойчи- 
вость к воздействию факторов внешней среды (высушивание, УФ-облучение, традиционно рекомендуемые концентрации дезинфицирующих средств).

Изучаемые штаммы S. typhimurium характеризовались выраженной антибиотикорезистентностью, имевшей идентичный характер (табл. 1). Следует отметить, что подавляющая часть выделенных штаммов S. typhimurium (более 97\%) была полностью резистентна кдействию 18 из 27 исследуемых антибиотиков, среди которых антибиотики пенициллинового ряда, значительная часть аминогликозидов, тетрациклины, цефалоспорины I-III поколений, макролиды, гликопептиды, антибиотики разных групп (левомицетин, рифампицин), сульфаниламидные препараты (триметоприм). На протяжении всей хронической эпидемии (33 мес.) выделяемые штаммы были чувствительны к препаратам фторхинолонового ряда, карбапенемам, полимиксину-М и умеренно чувствительны к ряду препаратов группы аминогликозидов II и III поколений (гентамицину, нетилмицину, амикацину), цефалоспорину IV поколения цефепиму.

\section{В подавляющем большинстве случаев (более 80\%) возбудителем нозокомиального сальмонеллеза как в России, так и за рубежом является S. typhimurium}

Следует отметить, что в течение наблюдения за хронической эпидемией, по данным антибиотикограмм, установлено снижение чувствительности сальмонелл к ряду антибиотиков, в частности аминогликозидов. Сроки возникновения устойчивых штаммов возбудителя при изначально высоком уровне чувствительности к антибиотику различны в отношении отдельных препаратов. Так, например, в отношении гентамицина и нетилмицина эти сроки составили около 6-7 мес., амикацина 23-25 мес. При этом важно подчеркнуть, что данные антибиотики не использовались в качестве этиотропной терапии сальмонеллеза.

При проведении исследования чувствительности культур, выделенных в ходе эпидемиологического наблюдения за очагом хронической эпидемии (1995-1996 гг.), к коммерческому препарату лечебного комплексного сальмонеллезного бактериофага групп ABCDE производства НПО «Иммунопрепарат» (г. Уфа) обнаружилась недостаточность лизирующего эффекта. Исследователями были предоставлены выделенные от больных штаммы S. typhimurium, позволившие производителю успешно адаптировать бактериофаг.

В современных условиях производство бактериофагов в России является особым уникальным направлением научнопроизводственной деятельности НПО «Микроген». В настоящее время компания располагает самой большой коллекцией терапевтических бактериофагов в мире.

Формирование множественной лекарственной устойчивости обусловлено наличием у госпитальных штаммов S. typhimurium конъюгативной R-плазмиды. Основной меха- низм лекарственной устойчивости, сообщаемой бактериям R-плазмидами, - приобретение клетками способности синтезировать энзимы, разрушающие химиотерапевтический препарат $[1-3,7,8,12,14]$. Широкое распространение множественной лекарственной устойчивости, детерминированной R-плазмидами, обусловлено в основном их селекционными преимуществами, связанными со способностью передавать устойчивость одновременно ко многим антибактериальным препаратам, используемым в практике, а также со способностью R-плазмид передаваться посредством конъюгации между бактериями, принадлежащими к разным типам, видам, родам и даже семействам [14].

Генетические исследования госпитальных штаммов, проводимые в различных странах, позволили установить неоднородность молекулярных масс плазмидных ДНК. Исследователями описаны плазмиды госпитальных штаммов сальмонелл с молекулярной массой $38 \mathrm{MDa}, 65 \mathrm{MDa}, 81 \mathrm{MDa}, 59 \mathrm{~kb}, 98,0$, 6,76 и 3,8 kb [3].

Нами совместно с профессором Г.Д. Каминским был исследован плазмидный профиль части выделенных штаммов S. typhimurium. B референс-коллекцию были включены 62 культуры. В результате проведенного исследования были выявлены типичный и нетипичный плазмидные профили. Типичный плазмидный профиль характерен для большинства исследованных штаммов (95,2\%) и представлен тремя плазмидами размером 128,7, 17,4 и 2,4 kb. Наличие плазмиды вирулентности размером 128,7 kb свидетельствовало об антропонозном происхождении возбудителя сальмонеллеза, и, что характерно для плазмид такого размера, в геном, вероятно, был включен фактор антибиотикорезистентности. Нетипичный профиль имели несколько штаммов: №8206, изолированный от больного и содержащий только одну плазмиду размером 128,7 kb; №11368, выделенный от больного и содержащий две плазмиды размером 137,4 и 2,4kb, и №17093, выделенный от больного, бесплазмидный. Последний из нетипичных профилей (№17093) получен от пациента после проведенного курса лечения фторхинолонами, хотя до проводимой терапии от данного больного

\section{Производство бактериофагов в России является особым уникальным направлением научно-производственной деятельности НПО «Микроген»}

изолировались культуры с типичным профилем. Обнаружение нетипичных плазмидных профилей позволяет также предполагать регулярность заносов инфекции извне на фоне хронической эпидемии. Коэффициент неоднородности популяции составил 0,05, что позволяет говорить о циркуляции именно госпитального штамма S. typhimurium в процессе хронической эпидемии.

Следует подчеркнуть, что возбудитель инфекции выделялся практически из всех биологических жидкостей и материалов, полученных от заболевших нозокомиальным 
Рисунок 1. Динамика заболеваемости нозокомиальным сальмонеллезом в крупном стационаре

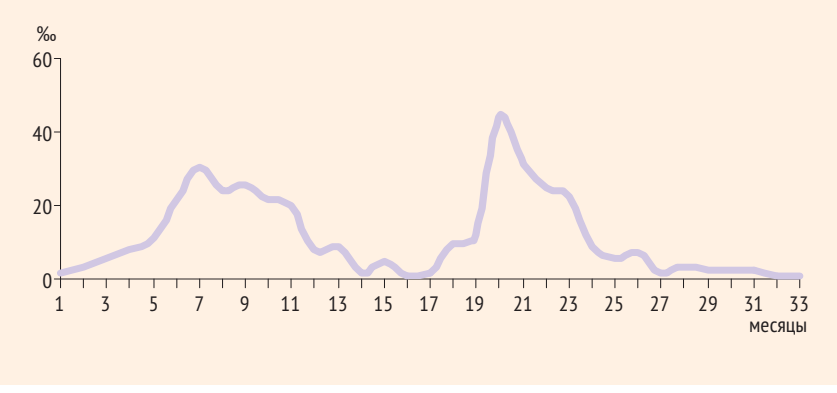

сальмонеллезом (табл. 2).Чаще всего возбудитель выделялся из кала и крови заболевших (более $80 \%$ ), однако, кроме того, отмечалось выделение S. typhimurium из мочи, желчи, экссудатов брюшной и грудной полостей, гнойного отделяемого ран, мокроты, а также секционного материала умерших, что свидетельствует о частоте генерализации и интенсивности течения инфекционного процесса в организме заболевших.

Занос госпитального штамма возбудителя в стационар происходит, как правило, одним из диагностически неясных поступающих пациентов, находящимся в инкубационном периоде заболевания, и при наличии предрасполагающих и сопутствующих факторов чаще всего приводит к формированию стойких, длительно существующих эпидемических очагов нозокомиальной инфекции. Многолетний опыт микробиологического исследования пациентов, поступающих в хирургические отделения крупного многопрофильного стационара, свидетельствуя о важности проблемы, наглядно демонстрирует, что 0,5-0,9\% из них выделяют полиантибиотикорезистентные штаммы S. typhimurium.

Динамика заболеваемости нозокомиальным сальмонеллезом, как водится, отличается постепенным подъъемом и последующим длительным торпидным течением во времени с выраженной тенденцией к хронизации эпидемического процесса. В динамике заболеваемости проявляется определенная волнообразность, характеризующаяся неравномерными временными периодами повышения и спада заболеваемости (рис. 1).

В проявлениях эпидемического процесса отмечается ярко выраженная тенденция заболеваемости нозокомиальным сальмонеллезом в холодное время года (индекс сезонности составляет 3,6-6).

Анализ структуры заболеваемости нозокомиальным сальмонеллезом по профилю отделений ЛПУ показывает, что более 90\% из числа всех заболевших регистрируются в отделениях хирургии и реанимации (рис. 2). Интенсивные показатели в них более чем в 10 раз превышают показатели заболеваемости в отделениях терапевтического профиля.

Анализ заболеваемости в отделениях реанимации позволяет установить, что наибольшие уровни ее отмечаются в отделениях общей реанимации, обслуживающих категорию больных после операций, преимущественно на органах брюшной полости. Среди профильных хирургических отделений наибольшие уровни заболеваемости, достоверно отличающиеся от других, отмечаются, как правило, в отделениях неотложной и абдоминальной хирургии, а также травматологии, в которых регистрируется более 75\% всех случаев сальмонеллезной инфекции, выявленных у хирургических больных ЛПу.

Характеристика структуры основной патологии пациентов стационара, заболевших сальмонеллезом, позволяет установить, что более чем у $80 \%$ из них инфекция развивается на фоне оперативных методов лечения острой патологии органов брюшной полости, онкологических заболеваний и травматических повреждений (рис. 3).

К основным факторам риска заражения и заболевания нозокомиальным сальмонеллезом относятся:

- оперативное вмешательство (преимущественно на органах брюшной полости) (75-80\%);

— лечение и пребывание в послеоперационном периоде в отделениях интенсивной терапии и реанимации (80-85\%);

- активная терапия гормонами, химиопрепаратами, антибиотиками (100\%);

च дисбактериоз (95-100\%);

口 пожилой возраст пациентов (более 75\% составляли лица старше 68 лет);

— хроническая патология органов и систем с признаками функциональной недостаточности (95-98\%).

Среди клинических форм сальмонеллезной инфекции преобладает гастроинтестинальная (85-90\%), генерализация инфекции отмечается в 10-15\% случаев. По тяжести клини-

Рисунок 2. Уровень и структура заболевших нозокомиальным сальмонеллезом пациентов по профилю отделений
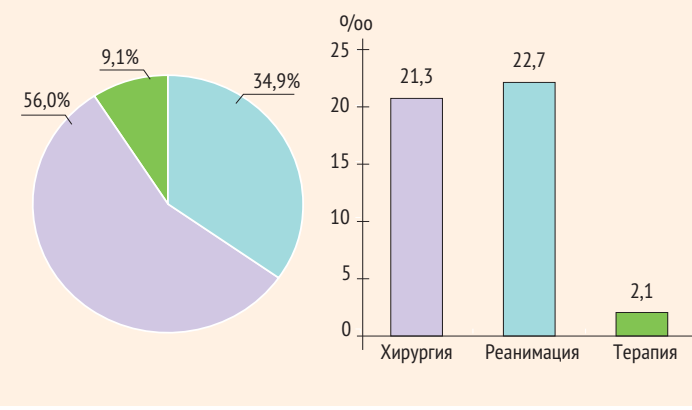

Рисунок 3. Структура основной патологии заболевших нозокомиальным сальмонеллезом пациентов

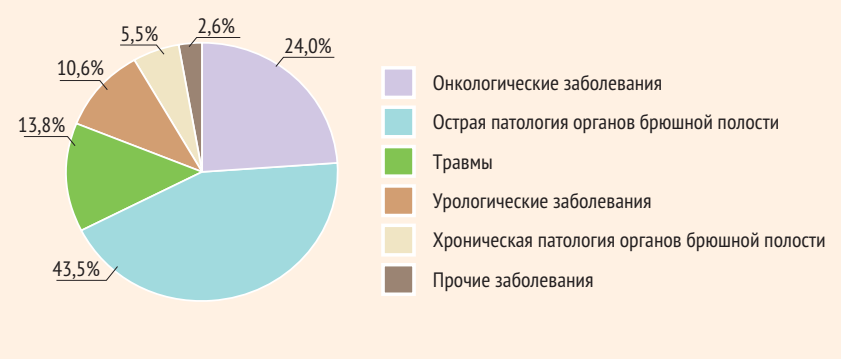


ческого течения (более 80\%) превалируют тяжелые и среднетяжелые формы инфекции. Летальность при нозокомиальном сальмонеллезе составляет от 3 до 8\%.

Нозокомиальный сальмонеллез в стационарах для взрослых характеризуется многообразием взаимосвязанных и взаимообусловленных путей и факторов передачи инфекционного агента. Выделяемые воздушно-пылевой (аспирационный), контактно-бытовой и алиментарный пути передачи возбудителя обладают определенной степенью самостоятельности и эпидемиологической активности. Тяжесть основного заболевания, выраженное влияние факторов риска, способствующих развитию иммуносупрессии, пожилой возраст пациентов, преобладание воздушно-пылевого пути передачи свидетельствуют о низкой заражающей дозе возбудителя, составляющей, вероятно, не более нескольких десятков микробных тел.

Медицинский персонал стационара активно вовлекается в эпидемический процесс нозокомиального сальмонеллеза, являясь его постоянно действующим звеном, и оказывает важное влияние на процессы хронизации его течения, формирования и поддержания стойких эпидемических очагов инфекции в связи с непосредственным участием в реализации путей передачи инфекционного агента. В структуре всех заболевших нозокомиальным сальмонеллезом в стационаре доля медицинского персонала может составлять от 5 до $10 \%$.

Специфика проявлений эпидемического процесса среди медицинского персонала характеризуется выраженной тенденцией от преобладания манифестных форм заболевания в начальный период эпидемии к бактерионосительству на ее последующих этапах.

Противоэпидемические мероприятия, проводимые в стационаре по поводу нозокомиального сальмонеллеза, сложны и трудоемки в организационном, эпидемиологическом и экономическом смысле и отличаются длительным характером. Указанные мероприятия редко носят исчерпывающий характер, способствуя временному снижению заболеваемости, что часто приводит к вынужденным мерам закрытия стационара с последующей заключительной дезинфекцией и капиталь-

\section{Рисунок 4. Длительность бактериовыделения саль-} монелл при различных вариантах терапии

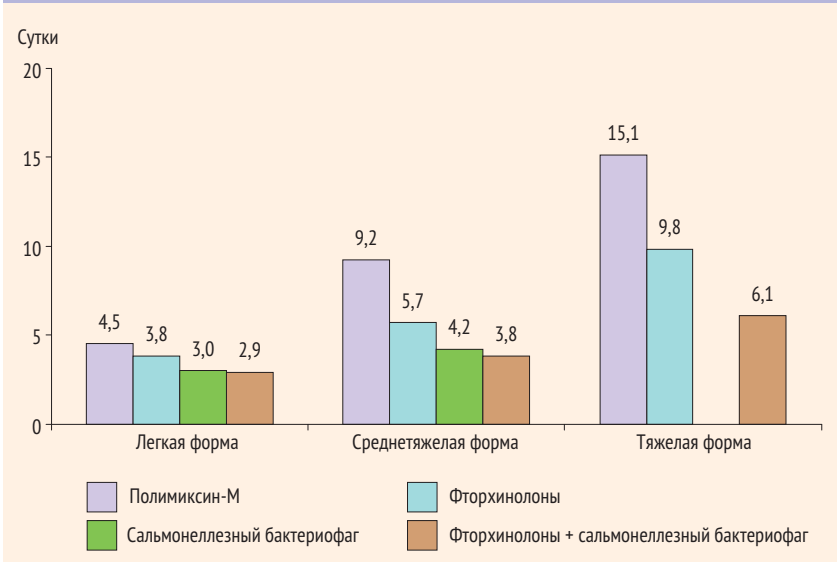

ным ремонтом пораженных корпусов. Однако в практической деятельности это далеко не всегда возможно, в связи с чем очень часто приходится проводить противоэпидемические мероприятия в условиях работающего стационара и в лучшем случае временного уменьшения загрузки наиболее пораженных отделений.

Работая в таких условиях, нами в системе противоэпидемических мероприятий, проводимых в стационаре, был применен метод комплексного многоцелевого использования адаптированного сальмонеллезного бактериофага. Бактериофаг использовался с целью лечения заболевших нозокомиальным сальмонеллезом пациентов ЛПу, фагопрофилактики находящихся и поступающих в эпидемический очаг больных, а также санации и фагопрофилактики сотрудников.

Эффективность ликвидации очагов сальмонеллеза в ЛПу зависит от своевременности, качества и целенаправленности проведения комплекса противоэпидемических мероприятий, ориентированных на все звенья эпидемического процесса. В отношении источника инфекции проводятся:

口 ранняя клиническая и лабораторная диагностика заболевания;

- ранняя изоляция заболевшего;

- назначение оптимальной этиотропной терапии заболевших нозокомиальным сальмонеллезом с использованием адаптированного сальмонеллезного бактериофага.

Проведенными исследованиями показано, что оптимальным вариантом клинически и эпидемиологически эффективной терапии является использование адаптированного сальмонеллезного бактериофага для лечения легкого и среднетяжелого течения гастроинтестинальной формы нозокомиального сальмонеллеза и применение его в комбинации с препаратами фторхинолонового ряда для лечения тяжелого течения гастроинтестинальной формы и клинических вариантов генерализованной формы инфекции. Бактериофаг назначали:

п при легких формах - по 2 табл. 3 раза в сутки (4-5 дней); п при среднетяжелых формах - по 2-3 табл. 3 раза в сутки (5-7 дней);

при тяжелых формах - по 3-4 табл. 3 раза в сутки (1214 дней) в комбинации с препаратами фторхинолонового ряда (5-7 дней).

Применение бактериофага позволяет сократить сроки бактериовыделения в 1,5-2,5 раза, уровень бактерионосительства в 6-20 раз в зависимости от используемых схем этиотропной терапии (рис. 4, 5), что имеет важное клиническое и эпидемиологическое значение.

В отношении мероприятий по разрыву путей передачи возбудителя предусматривается:

— влажная уборка палат (не менее 2 раз в день);

— текущая и заключительная дезинфекция в очаге;

- дезинфекция воздуха палат и нормализация параметров микроклимата;

- обработка и дезинфекция инструментария и аппаратуры;

камерная дезинфекция постельных принадлежностей и матрацев; 
контроль за соблюдением санитарно-гигиенических норм работы пищеблока и обследование работников питания.

В отношении восприимчивых контингентов (пациенты и медицинский персонал), поступающих в очаг нозокомиального сальмонеллеза, впервые в российской и зарубежной практике нами разработана и применена методика санации и профилактики с использованием сальмонеллезного бактериофага. Рекомендуется профилактическое назначение адаптированного сальмонеллезного бактериофага всем поступающим в отделения пациентам с высоким риском заражения и находившимся в контакте с больными нозокомиальным сальмонеллезом из расчета по 2 табл. 2-3 раза в сутки (первые 5 дней), затем по 2 табл. однократно ежедневно в течение времени пребывания в очаге. Проводится санация и фагопрофилактика медицинского персонала. Санация сотрудников отделений с высоким риском заражения проводится сальмонеллезным бактериофагом из расчета по 2-4 табл. 3 раза в сутки (5-7 дней) с плавным переходом на фагопрофилактику с назначением бактериофага по 2 табл. 3 раза в неделю в течение времени существования эпидемического очага.

Давая оценку эпидемиологической эффективности многоцелевого комплексного использования бактериофага при включении его в систему противоэпидемических мероприятий, следует подчеркнуть, что бактериофаг нами стал эксплуатироваться через 29 мес. от начала хронической эпиде-

Рисунок 5. Частота острого бактерионосительства сальмонелл при различных схемах терапии

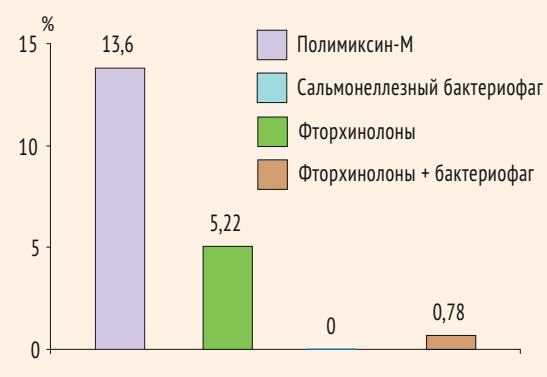

Рисунок 6. Эпидемиологический прогноз и зффективность противоэпидемических мероприятий в очаге нозокомиального сальмонеллеза

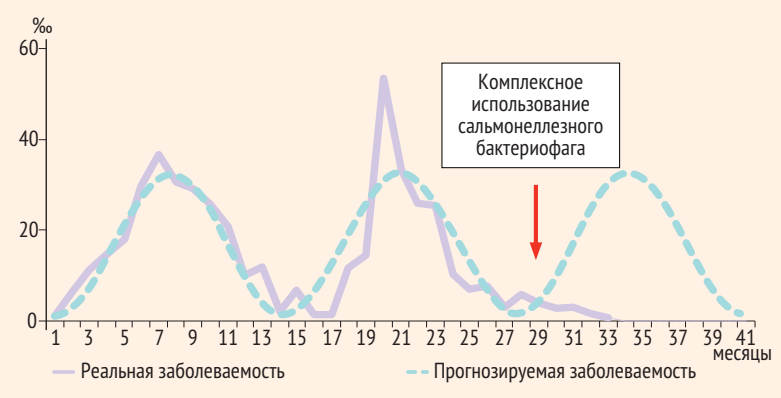

мии. В стационаре к этому времени был сформирован стойкий очаг нозокомиального сальмонеллеза на фоне постоянно выполняемого комплекса традиционно рекомендуемых противоэпидемических мероприятий, что демонстрировало фактическую их несостоятельность. Широкое и многоцелевое применение адаптированного сальмонеллезного бактериофага (рис. б) в комплексе противоэпидемических мероприятий позволило выявить высокую клиническую и эпидемиологическую эффективность его употребления в целях локализации и ликвидации длительно существующих эпидемических очагов нозокомиального сальмонеллеза.

\section{- Применение бактериофага позволяет сократить сроки бактериовыделения$$
\text { в 1,5-2,5 раза, }
$$ уровень бактерионосительства в 6-20 pa3}

Оценка качества противоэпидемических мероприятий и прогнозирование течения эпидемического процесса в крупном очаге нозокомиального сальмонеллеза проводилось на базе специально разработанной совместно с ведущим научным сотрудником Института проблем информатики РАН профессором Гринченко С.Н. математической модели. Для построения модели использован метод наименьших квадратов (рис. 6). Анализ представленных кривых показывает, что осуществленные начиная с 30-го месяца противоэпидемические мероприятия обусловили кардинальное изменение хода эпидемического процесса, снизив заболеваемость за 4 месяца до нулевой отметки и позволив предотвратить заболевание 300-315 пациентов в течение прогнозируемого периода (эпидемического года).

Учитывая эпидемиологические особенности нозокомиального сальмонеллеза, сроки реализации всего комплекса противоэпидемических мероприятий и эпидемиологического наблюдения за очагом с единичным случаем заболевания должны составлять 2-3 мес., а для очага с множественными случаями заболеваний - не менее 6-12 мес. после последнего бактериологически подтвержденного случая манифестной формы заболевания или носительства, выявленного в эпидемическом очаге.

Предлагаемый метод комплексного использования бактериофага является высокоэффективным и безвредным при лечении заболевших, позволяет надежно осуществлять профилактику заболевания при поступлении контингентов риска в эпидемический очаг и санацию сотрудников и, что немаловажно, весьма экономичен. Использование данного метода поможет стационару с емкостью 1,5-2 тыс. коек, не прекращая его деятельности, уменьшить затраты на проведение противоэпидемических мероприятий по поводу ликвидации эпидемического очага нозокомиального сальмонеллеза в 20-50 раз и сэкономить до 25-30 млн руб.

Анализ научно-практических публикаций и получаемых отзывов свидетельствует о воспроизводимости метода, 
впервые опубликованного в 1998 г. в центральных научных журналах, и его эффективном использовании в последующем в целом ряде крупных ЛПу различных регионов и субъектов РФ.

Таким образом, нозокомиальный сальмонеллез как одна из насущных проблем ВБИ для современного здравоохранения представляет собой антропонозную ветвь эволюционного развития эпидемического процесса сальмонеллезной инфекции, которая приобрела особые специфические черты под воздействием социальных факторов в XX столетии и является одним из наглядных доказательных примеров социально-экологической концепции [13]. Учитывая высокий уровень заболеваемости данной инфекцией в ЛПУ РФ, нозокомиальный сальмонеллез требует дальнейшего всестороннего изучения.

\section{ЛИТЕРАТУРА}

1. Акимкин В.Г. Нозокомиальный сальмонеллез как самостоятельная нозологическая форма инфекционной патологии человека // Эпидемиология и инфекционные болезни. 1998. №2. C. $49-54$.

2. Акимкин В.Г. Эпидемиология и профилактика нозокомиального сальмонеллеза в стационарах для взрослых // Эпидемиология и инфекционные болезни. 1998. №3. С. 18-24.

3. Акимкин В.Г., Покровский В.И. Нозокомиальный сальмонеллез взрослых. М.: Издательство PAMH, 2002.

4. Бродов Л. Е., Малеев В. В., Ющук Н.Д. О нозопаразитической форме сальмонеллеза // Журн. микробиол. 1996. №1. С. 78-80.

5. Покровский В.И., Семина Н.А. Внутрибольничные инфекции: проблемы и пути решения // Эпидемиология и инфекционные болезни. 2000. №5. С. 12-14.

6. Покровский В.И. Проблемы внутрибольничных инфекций // Эпидемиология и инфекционные болезни. 1996. №2. С. 4-9.

7. Покровский В.И., Килессо В.А., Ющук Н.Д. [и др.]. Сальмонеллезы (этиология, эпидемиология, клиника, профилактика). Ташкент: Медицина, 1989.

8. Практическое руководство по антиинфекционной химиотерапии / под ред. Л. С. Страчунского, Ю. Б. Белоусова, С. Н. Козлова. М., 2002.

9. Профилактика внутрибольничных инфекций: Руководство для врачей / под ред. Е.П. Ковалевой, Н.А. Семиной. М.: ТОО «Рарогъ». 1993.

10. Руководство по эпидемиологии инфекционных болезней / под ред. В.И. Покровского. М.: Медицина, 1993.

11. Семина Н.А., Ковалева Е.П., Тихомиров Е.Д. Внутрибольничные инфекции // Руководство «Эпидемиология инфекционных болезней» / под ред. В.И. Покровского. М.: Медицина, 1991. T. 1. С. $452-462$.

12. Справочник госпитального эпидемиолога. М.: Хризостом, 1999.

13. Черкасский Б. Л. Руководство по общей эпидемиологии. М.: Медицина, 2001.

14. Яфаев Р.Х., Зуева Л.П. Эпидемиология внутрибольничной инфекции. Л.: Медицина, 1989.

15. Campo P., Gutiqrrez A., Ladryn de Guevara C. Evolution of susceptibility of non-typhi Salmonella in a Spanish hospital (1992-1994) and report of a Salmonella ser. typhimurium isolate resistant to quinolones // Eur.J. Epidemiol. 1997. Vol. 13. №2. P. 239-241.

16. Fernandez Guerrero Manuel L., Perea Rafael Torres, Gomes Rodrigo Javier et al. Infectious endocarditis due to non-typhi Salmonella in patients infected with human immunodeficiency virus: Report of two cases and review // Clin. Infect. Diseases. 1996. Vol. 22. №5. P. 853-855.

17. Kam Kai-Man. Serotype epidemiology and patterns of antibiotic susceptibilities of salmonellae isolated in Hong Kong 1983-1993 // Clin. Med.J. 1996. Vol. 109. №4. P. 276-281.

18. Torres J. R., Gotuzzo E., Isturiz R. et al. Salmonella splenic abscess the antibiotic era: A Latin American perspective // Clin. Infect. Diseases. 1994. Vol. 19. №5. P. 871-875. 